\title{
Taking local optics outreach abroad for IYL 2015: administrative and logistical challenges and strategies
}

Nicholas H. Wong, Matthew Posner, Vinita Mittal, David Gray, Pearl John

Nicholas H. L. Wong, Matthew T. Posner, Vinita Mittal, David R. Gray, Pearl V. John, "Taking local optics outreach abroad for IYL 2015: administrative and logistical challenges and strategies," Proc. SPIE 9946, Optics Education and Outreach IV, 99460F (27 September 2016); doi: 10.1117/12.2237442

SPIE Event: SPIE Optical Engineering + Applications, 2016, San Diego, California, United States 


\title{
Taking local optics outreach abroad for IYL 2015: administrative and logistical challenges and strategies
}

\author{
Nicholas H. L. Wong ${ }^{\mathrm{a}}$, Matthew T. Posner ${ }^{\mathrm{a}}$, Vinita Mittal ${ }^{\mathrm{a}}$, David R. Gray ${ }^{\mathrm{a}}$, and Pearl V. \\ $\mathrm{John}^{\mathrm{b}}$ \\ ${ }^{a}$ Optoelectronics Research Centre, University of Southampton, Southampton SO17 1BJ, UK \\ ${ }^{\mathrm{b}}$ Physics and Astronomy, University of Southampton, Southampton SO17 1BJ, UK
}

\begin{abstract}
The Lightwave Roadshow is an outreach program run by research students at the University of Southampton, UK, that seeks to educate and inspire young students with optics, through conducting workshops in local schools and exhibiting at local and regional educational fairs. Adopting a hands-on philosophy enabled by an extensive collection of experimental optical demonstrations, Lightwave aims to promote scientific interest and indirectly address the global STEM skills shortage. While Lightwave has become a well-established program in local schools since its inception in 1998, 2015 included an unprecedented number of overseas activities. Inspired by the International Year of Light and Light-based Technologies (IYL 2015), Lightwave organized a school workshop in a foreign country (Singapore) as well as exhibited at major events, including the IYL 2015 opening ceremony in France, which marked the first time that the roadshow used UK school students to deliver outreach activities beyond the UK. These recent successful overseas projects have encouraged the outreach team to continue expanding the reach of the roadshow internationally. Of particular note is the involvement of Lightwave at academic conferences, where experiences and best practices can be shared among outreach ambassadors from different programs, student chapters, universities, and organizations. This paper provides a review of these activities, and identifies the administrative and practical challenges of bringing a local outreach program abroad and some strategies to overcome them. We also outline our travel suite of experimental demonstration kit, a portable selection from our main equipment inventory. This won the recent OSA 'IYL-To-Go' student competition.
\end{abstract}

Keywords: Optics education, Photonics outreach, International outreach, Public engagement, Outreach logistics, Student chapter, IYL 2015, STEM

\section{INTRODUCTION}

Programs for educational outreach in optics and photonics are common in numerous universities and science organizations. Such programs can begin by establishing a system of visits to local primary and/or secondary schools, and possibly gradually expand to include fair exhibitions. This is the case for the Lightwave Roadshow, a graduate student-led optics education and outreach program at the University of Southampton, United Kingdom (UK). With a view to broaden the roadshow's reach, we endeavored to increase its international presence, notably during 2015's International Year of Light (IYL 2015). This led to the Lightwave team conducting school workshops outside the UK and exhibiting at a number of international conferences and events including the IYL 2015 opening ceremony in Paris, France, and in the United States for the Optical Fiber Communications Conference and Exhibition (OFC) in Los Angeles, CA; SPIE Optics + Photonics in San Diego, CA; and Frontiers in Optics/Laser Science (FiO/LS) in San Jose, CA. In this paper, we discuss some challenges of, and associated strategies for, doing outreach abroad. Experiences are shared that may be useful to other university or organization teams and programs.

Sec. 2 provides a background to the Lightwave Roadshow and the context for overseas outreach. Secs. 3-5 address issues relevant to general, exhibition, and workshop settings for the activities, respectively. Several case examples of prior events are given. Finally, we detail an example of the demonstrations which we use, contained in a portable, single-person operable optics outreach kit in Sec. 6, and conclude the paper in Sec. 7.

Further author information: (Send correspondence to N.H.L.W.)

N.H.L.W.: E-mail: nhlw1g12@soton.ac.uk, Telephone: +44 2380593173

Optics Education and Outreach IV, edited by G. Groot Gregory, Proc. of SPIE Vol. 9946, 99460F (C) 2016 SPIE · CCC code: $0277-786 \mathrm{X} / 16 / \$ 18 \cdot$ doi: $10.1117 / 12.2237442$ 


\section{BACKGROUND}

\subsection{The University of Southampton Optics and Photonics Society}

The Optics and Photonics Society (OPSoc) at the University of Southampton (UoS) is a student-led campus society that brings together students from various light and optics focused disciplines. In 1994, a group of doctoral $(\mathrm{PhD})$ students from the Optoelectronics Research Centre (ORC) at the university established a local student chapter of The Optical Society (OSA), the first of its kind outside the United States. ${ }^{1}$ The goal was, and still is, to provide an environment for research students and staff to communicate their research and other ideas as well as to enhance their professional development, through academic, outreach, and social interactions at annual and other activities and events. ${ }^{2}$ Over the years, the original OSA chapter expanded to encompass the establishment of an SPIE student chapter in 2011 and an IEEE Photonics Society (IPS) student chapter branch in 2016, and became what is OPSoc today. OPSoc's outreach aspect is called the Lightwave Roadshow.

\subsection{The Lightwave Roadshow}

In 1998, the then OSA student chapter was called upon to build simple optics experiments for school workshops for children within the ages of 5 to 11 years. The success of these initial events led to the development of an ever growing permanent suite of optics kits as part of a traveling 'show'. Hence, the Lightwave Roadshow was created. ${ }^{3}$ Over time, the roadshow has established its presence in the Southampton region. Apart from the traditional school visits, Lightwave has also diversified its delivery format to include exhibiting at fairs, and conducting on-campus classes for primary and secondary school students visiting the university. These activities are all supported by a team of $\mathrm{PhD}$ student demonstrators or Lightwave Ambassadors. The aim of the roadshow is to do its part to address the science, technology, engineering, and mathematics (STEM) skills shortage by getting students introduced to and interested in optics from a young age. This is done through a philosophy of providing participants with the experience of inspiring hands-on experiments and demonstrations given by enthusiastic researchers acting as positive role models. The Lightwave Roadshow has been thoroughly detailed previously, up till July 2015, in Ref. 4, along with a current shift to incorporate public engagement with research (PER) into its educational outreach activities.

Recently, the roadshow has developed collaborations with university and external parties to enhance its reach and impact. These include, among others,

- A university collaboration with UoS. Through the university's "Learn with US (Outreach)" program, which includes the Year 6 STEM Carousel Day, and Years 7-10 university visits, ${ }^{5,6}$ we conduct optics classes for students visiting the university to motivate them to consider pursuing higher education.

- An external collaboration with a local business. The Lightwave team worked with Elks-Smith Garden Design (http://www.elks-smith.co.uk/) to create a photonics-themed show garden, called "Reflecting Photonics", to celebrate the International Year of Light. The award-winning garden was shown at the 2015 Royal Horticultural Society Flower Show Tatton Park, ${ }^{7}$ and was used by Lightwave ambassadors to engage the public with their research.

The roadshow has also made major contributions to UoS's input to Photonics4All (http://photonics4 all.eu/), a European Union funded project from the Horizon 2020 research and innovation program that promotes photonics to school children, the general public, and entrepreneurs. We have helped to produce optics quizzes in multiple languages for secondary school pupils, and have edited photonics bookmarks which have been disseminated to thousands of people during outreach activities across Europe.

\subsection{The International Year of Light and Light-based Technologies}

Light, in its natural and harnessed forms, plays a pervasive role in daily life, ranging in applications from communications to energy, from agriculture to healthcare. In seeking to recognize the importance of light and to spread international awareness of how light is vital for both contemporary society and solving future technical and societal problems, as well as to commemorate the anniversaries of several key optical science and engineering milestones, the United Nations General Assembly 68th Session proclaimed 2015 as the "International Year of 
Light and Light-based Technologies" (IYL 2015). ${ }^{8}$ Numerous events and initiatives, at all levels - local, regional, national, and global - were organized by schools, universities, companies, governmental agencies, and individuals to celebrate light. These included special conference sessions, art festivals, public displays, and commemorative coins, stamps, postcards, etc., to name a few. ${ }^{9-13}$

\subsection{Motivation for International Outreach}

Up until recently, the Lightwave Roadshow's activities were largely concentrated around the local Southampton and southern England regions, with occasional fairs slightly further away, e.g. the 2014 Big Bang Fair ${ }^{14}$ in Birmingham. In 2009, Lightwave ambassadors and then PhD students Mohammad Belal and Nikita Daga conducted optics outreach with residents of rural villages in Uttar Pradesh, India, while on vacation back in their home country. This initiated the roadshow's first international appearance. Albeit being one-off, it greatly contributed to one of Lightwave's key goals of reaching more and new audiences, and the success of that event encouraged the prospect of future engagements abroad.

IYL 2015 was a springboard to raise awarenes of optics and photonics to new audiences worldwide. Under the auspices of this global observance, opportunities emerged to increase Lightwave's reach, e.g. to new countries, as well as to target new audiences, notably, sharing ideas at international conferences with other educators and contemporaries running analogous outreach programs in other universities. Particular instances of these are detailed in the case examples in the following sections.

\section{CONSIDERATIONS FOR GENERAL OVERSEAS OUTREACH}

In this section, we discuss a number of considerations and challenges that apply to outreach activities regardless of format; Secs. 4 and 5 cover issues specific to exhibitions and school workshops, respectively. While the considerations mentioned here pertain to outreach taken overseas, many are also relevant to general activities in local settings. One difference between local and overseas outreach is the number of ambassadors demonstrating at the events. Whereas local exhibition and school visits are made by teams of at least two or more demonstrators, oftentimes, due to funding constraints and/or demonstrator availability, the analogous overseas activities are conducted by a single ambassador traveling alone, perhaps conducting a workshop in their home country or exhibiting at a conference. The following points address issues in this context.

\subsection{Training}

An ambassador traveling alone needs to solely manage all facets of an activity whilst abroad, from transport to equipment to the actual engagement and evaluation. It is thus important to ensure that they are experienced and confident with all such logistics. Whenever students are about to travel and opportunities are open for them to deliver Lightwave activities abroad, it is usual, if they are new to outreach, for them to participate in one or more local Lightwave events (of the appropriate format) prior to traveling. For example, a student who plans to conduct a class workshop in a school overseas would first be encouraged to join, and better yet lead, a local school visit, in order to experience first-hand the procedure and build confidence to be able to address any nuances of the activity.

Of course, opportunities for pre-travel training may not always be present, and in such cases, a verbal briefing and procedure rundown with the Lightwave director or other experienced leaders or university staff will suffice.

\subsection{Laser Safety}

Many demonstrations, such as those depicted in Fig. 1, use lasers and laser pointers rated up to Class II ( $\leq 1 \mathrm{~mW})$. While demonstrators may have undergone necessary laser safety training, the outreach audience, which includes school children, teachers, parents, and other non-specialists, would by and large not. Therefore, it is critical that demonstrators maintain control of all lasers and their operation. The following rules of thumb should serve as general advice:

- Ensure that lasers are never pointed at the audience. Experiments such as the Tyndall-Colladon experiment can be viewed safely from the side. Care must be taken in the set-up of experiments involving multiple-angle reflections; these must be blocked off before showing to an audience. 
- Restrict handling of lasers to demonstrators only. If demonstrators wish to provide hands-on opportunities to the audience, consider slotted light-emitting diode (LED) sources, such as the Light Blox kit. ${ }^{15}$

- Account for all lasers at the end of the activity.

- Remove batteries from laser pointers when traveling, especially by air.

- If possible, pack lasers in checked baggage when flying.

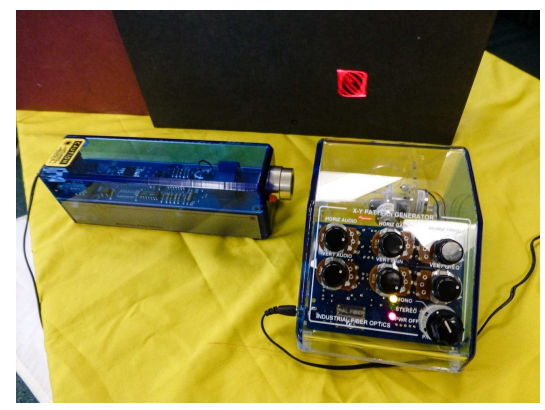

(a)

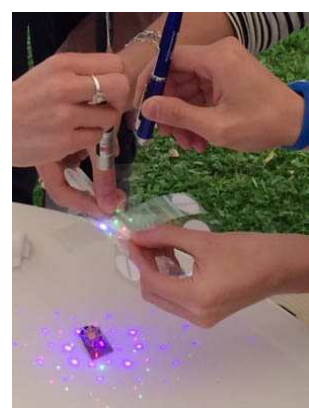

(b)

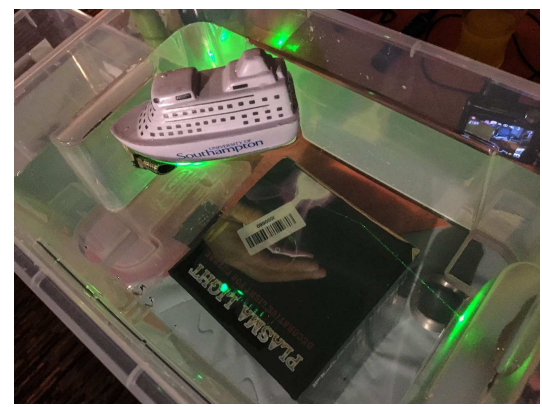

(c)

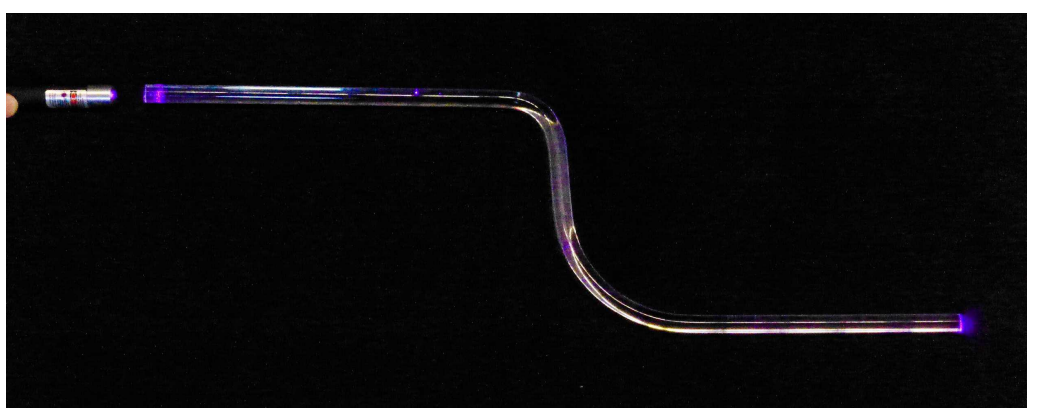

(d)

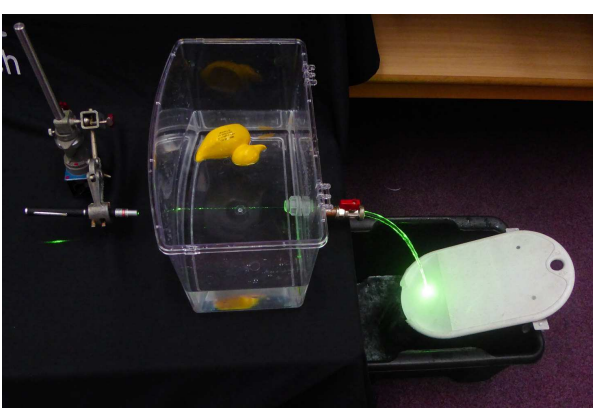

(e)

Figure 1: Demonstrations involving lasers: (a) modulated laser projection in a light show; (b) diffraction using laser pointers and grating sheets; (c) total internal reflection at a water surface; (d) waveguide guidance using a laser pointer and a bent Perspex rod; (e) Tyndall-Colladon experiment (light guidance in water).

\subsection{Portability}

A key requirement for demonstration kit used abroad is portability for air travel. Unless there is an available postal address in the destination city, all equipment must be transported by passenger, and a lone ambassador is restricted in space by their luggage capacity, and in weight by airline limitations and their own physical strength. The usage of small equipment that can fit into shoebox-sized containers has been found to be an efficient solution to these problems. The market has many small kits that are able to demonstrate equivalent optics experiments as their larger conventional counterparts. A useful guide for an exhibition format is to ensure that all equipment, when laid out for presentation, can fit on a $4 \mathrm{ft} \times 2 \mathrm{ft}(1.22 \mathrm{~m} \times 0.61 \mathrm{~m})$ tabletop. Sec. 6 outlines an example kit that we have used successfully at numerous overseas events.

\subsection{Publicity}

Pre-, mid-, and post-event news are all crucial for generating publicity and raising the profile of Lightwave. These can range from social networking and blog posts, to department and university stories, and even academic papers such as this. Photographs of ambassadors in action engaging with students or the public is useful for this purpose. Unfortunately, it is prohibitive for lone ambassadors to capture such footage while simultaneously demonstrating. In this case, it may be possible to acquire footage from the official conference or event photographer. In certain scenarios where this is absent, the ambassador can make prior arrangements for a teacher to take photographs 
during a school visit, or request non-audience passers-by to help take ad hoc footage at a fair. A caution to note is that some schools may have policies disallowing photography in order to protect the identities of minors. In all cases, permission should be sought for bringing a personal camera, and if given, then it is best to rely as far as possible on footage from said camera; footage of the engagement from other cameras, even if it exists, is not guaranteed to be readily available.

Timely publication of posts is a cornerstone of good publicity. Certain publicity types, e.g. website news or written articles, allow for some delay between the event occurring and publication. Other types however, e.g. social networking posts or tweets, may be more time-sensitive. Some venues might not provide adequate internet connectivity. To this end, as well as for general telephony, it may be useful to invest in a local mobile SIM card that provides a cellular data plan. Many cities have numerous options for foreign visitors, and it is prudent to check this before traveling.

Handing out giveaways is also a good way to increase publicity and provides a means for the audience to remember the engagement, especially for young students and children who are usually thrilled to receive gifts. To make engagements more memorable, we focus on handing out giveaways that are either commemorative, such as IYL 2015 pins (Fig. 4, left), or educational, such as diffraction gratings (Fig. 6, top right). These have the added benefit of allowing for advertising the logos of our sponsors and supporters.

\subsection{Funding}

Typically, the biggest costs for overseas outreach relate to getting the ambassador physically to the activity destination, i.e. travel and lodging expenses. In most cases, where the ambassador is traveling primarily to present at an academic conference and conducting an outreach activity secondarily, travel and accommodations are normally already covered by a research grant. However, in situations (such as this SPIE Optics + Photonics conference (OP16)) where the presenters are not traveling primarily for their own academic research but rather specifically for outreach, other funds may be available from various sources. These may be in the form of student travel grants, specific university funds, public engagement funds from organizations like the Engineering and Physical Sciences Research Council (EPSRC), or others. Tab. 1 lists (inexhaustively) a few sources, some of which were used to sponsor the authors presenting at OP16. We note that while there are myriad conference grants available, most of those listed here are unique in that they do not require paper acceptance.

Table 1: Grants available for supporting the travel aspects of overseas outreach. Amounts are in US\$, except where specified, and are correct as of July 2016. Italicized grants were used to sponsor two authors to present at OP16.

\begin{tabular}{|c|c|c|c|c|}
\hline Provider & Grant & Amount (Approx.) & Coverage & Event(s) \\
\hline \multirow[t]{2}{*}{ SPIE } & $\begin{array}{l}\text { Student Author Travel } \\
\text { Grant }^{16}\end{array}$ & $\$ 300-\$ 750$ & Transport; lodging & $\begin{array}{l}\text { Various SPIE } \\
\text { conferences }\end{array}$ \\
\hline & Officer Travel Grant ${ }^{17}$ & $\begin{array}{l}\$ 1,100-\$ 2,500 \text { (varies } \\
\text { by region) }\end{array}$ & $\begin{array}{l}\text { Transport; lodging; } \\
\text { food; registration }\end{array}$ & $\begin{array}{l}\text { Various SPIE } \\
\text { conferences }\end{array}$ \\
\hline OSA & $\begin{array}{l}\text { Student Leadership } \\
\text { Conference Grant }^{18}\end{array}$ & According to coverage & $\begin{array}{l}\text { Airfare; lodging ( } 3 \\
\text { nights); registration }\end{array}$ & $\mathrm{FiO} / \mathrm{LS}$ \\
\hline IPS & $\begin{array}{l}\text { Educational Seed } \\
\text { Grant }\end{array}$ & $\$ 1,000$ per cycle & Negotiable & Various outreach \\
\hline $\mathrm{UoS}$ & $\begin{array}{l}\text { Public Engagement } \\
\text { with Research grant } \\
\end{array}$ & $£ 1,000(\sim \$ 1,320)$ & $\begin{array}{l}\text { Transport; lodging; } \\
\text { registration }\end{array}$ & Various PER \\
\hline EPSRC & $\begin{array}{l}\text { Future Photonics Hub } \\
\text { outreach fund }^{20}\end{array}$ & $\begin{array}{l}£ 10,000(\sim \$ 13,200) \\
\text { for all } 2016 \text { projects; } \\
\text { varies by year }\end{array}$ & Negotiable & Various outreach \\
\hline ORC & Department funds ${ }^{4}$ & $€ 2,500(\sim \$ 2,760)$ & $\begin{array}{l}\text { Transport; lodging; } \\
\text { food }\end{array}$ & $\begin{array}{l}\text { IYL } 2015 \text { Opening } \\
\text { Ceremony }\end{array}$ \\
\hline
\end{tabular}


There is also funding available for purchasing and maintaining demonstration equipment including those required for mobile outreach, as well as for developing programs and activities. These generally come from professional optics or physics societies and require the existence of a corresponding established chapter for access. Some of these are listed in Tab. 2. As can be observed, the IYL 2015 celebration saw many societies offering special activity grants, enabling many of Lightwave's overseas engagements.

Table 2: Grants available for optics outreach equipment and activity development. Amounts may be subject to change in subsequent years.

\begin{tabular}{|c|c|c|c|c|}
\hline Provider & Grant & Amount (Max.) & Type & Frequency \\
\hline \multirow[t]{2}{*}{ SPIE } & $\begin{array}{l}\text { Educational Outreach Grants } \\
\text { Program }^{21}\end{array}$ & $\begin{array}{l}\$ 5,000 \text { first time; } \\
\$ 2,000 \text { sustaining }\end{array}$ & Normal & Biannual \\
\hline & $\begin{array}{l}\text { International Year of Light Activity } \\
\text { Grant }^{22,23}\end{array}$ & $\$ 5,000$ & Special & 2015 only \\
\hline \multirow[t]{4}{*}{ OSA } & Chapter/Section Management Grant ${ }^{24}$ & $\$ 800$ & Normal & Annual \\
\hline & Centennial Special Events Grant ${ }^{24}$ & $\$ 2,000$ & Special & 2016 only \\
\hline & $\begin{array}{l}\text { Student Chapter and Local Section } \\
\text { Excellence Prize }^{25}\end{array}$ & $\$ 250-\$ 500$ & Competition & Annual \\
\hline & $\begin{array}{l}\text { FiO/LS Student Chapter } \\
\text { Competition }\end{array}$ & $\$ 500$ & Competition & Annual \\
\hline \multirow[t]{2}{*}{ IPS } & Educational Seed Grant & $\$ 1,000$ per cycle & Normal & Periodic \\
\hline & IYL 2015 Chapter Challenge Grant ${ }^{27}$ & $\$ 1,500$ & Special & 2015 only \\
\hline \multirow{2}{*}{$\begin{array}{l}\text { European } \\
\text { Physical } \\
\text { Society (EPS) }\end{array}$} & $\begin{array}{l}\text { Young Minds (YM) Section Activity } \\
\text { Grant }^{28}\end{array}$ & $\begin{array}{l}€ 1,000(\sim \$ 1,100) \\
\text { per year }\end{array}$ & Normal & Biannual \\
\hline & IYL YM Activity Grant ${ }^{29}$ & $€ 500(\sim \$ 550)$ & Special & 2015 only \\
\hline
\end{tabular}

\section{CONSIDERATIONS FOR OVERSEAS EXHIBITIONS}

This section considers issues specific to outreach at exhibitions and fairs. As before, the context assumes solo demonstration.

\subsection{Topical Coverage}

The scope of the Lightwave Roadshow can be generalized to include any and all topics related to light. This invites endless possibilities for what is demonstrated. Of course, travel space and weight restrictions place a natural limit; see Sec. 3.3. Some outreach groups focus on a single key experiment that maximizes use of the available table or booth space. On the other hand, the Lightwave formula has been to showcase a diversity of optics topics to emphasize the ubiquity of light and its applications.

There are many topics, e.g. color, lasers, telecommunications, vision, etc., from which experiments can be constructed or commercially available kits procured. As each topic entails its own hardware, there is therefore a need to balance the number of topically diverse items with the amount of display space available, and moreover, with the amount of information about the topics that a single ambassador can communicate to the audience in a short time.

A solution we have found, as outlined in more detail in Sec. 6, is that four topics (each with their own corresponding equipment) can nicely fit on a $4 \mathrm{ft} \times 2 \mathrm{ft}(1.22 \mathrm{~m} \times 0.61 \mathrm{~m})$ tabletop and is manageable for one demonstrator, spending about 1-3 minutes per topic, to give a rounded educational pitch within 10 minutes. 


\subsection{Power}

Power is an issue that is sometimes overlooked. Since there is no guarantee that there will be any available mains outlet at or near the allocated exhibition space, it is ideal to utilize equipment that is battery operated or non-electrical. While batteries (rechargeable or not) are very portable, some demonstrators may be averse to using them due to them being deemed as additional loose parts that need to be remembered (and restocked in the case of non-rechargeables). USB powerbanks provide a 'cleaner' alternative. Most tabletop versions of optics kits have the option to be powered via USB and fully-charged powerbanks can normally last at least a day for anything other than high-consumption equipment. As a bonus for exhibiting at conferences, there are usually many opportunities to acquire giveaway powerbanks, free of charge, from other industry or company exhibitors. These can be essential in emergency situations, provided that displaying other company brands is not a problem. Fig. 2 shows several battery and powerbank powered kits.
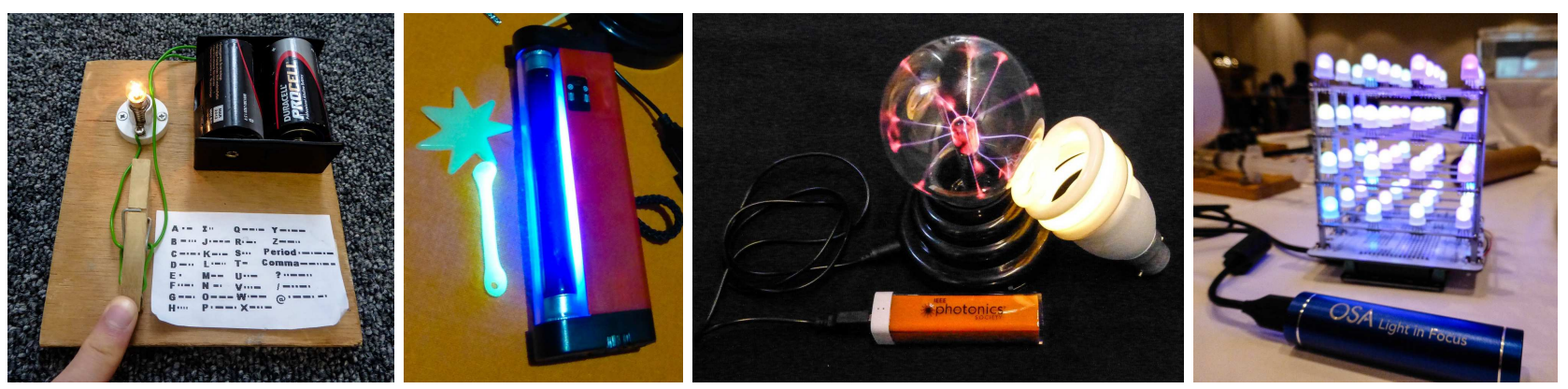

Figure 2: (Left to right) Battery operated kits: Morse code circuit, and ultraviolet lamp; and powerbank operated kits: plasma globe and fluorescence bulb, and LED matrix.

\subsection{Case Example: Exhibition at 2015 SPIE Optics + Photonics Conference}

Co-author Vinita Mittal was awarded the SPIE Officer Travel Grant ${ }^{17}$ and in August 2015, attended the Student Chapter Leadership Workshop at the SPIE Optics + Photonics conference (OP15) in San Diego, CA, USA, where she also took part in their sixth annual "Optics Outreach Games", representing the University of Southampton SPIE Student Chapter and the Lightwave Roadshow. While participating in the mutual sharing of ideas among fellow student chapters, she demonstrated a suite of experiments, named "Behavior of Light". Using simple and portable equipment, a number of which originate from the Optics Outreach Kit supplied to SPIE student chapters, she demonstrated reflection, refraction, diffraction, lens effects, and waveguide and optical fiber guidance. These items all fit in a travel kit dubbed the "Optics Handbag". Images of the engagement are shown in Fig. 3.
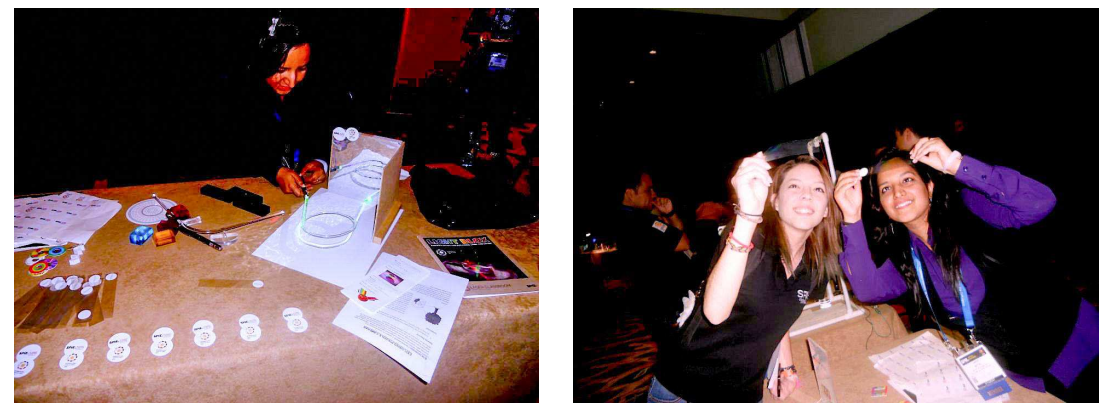

Figure 3: Lightwave ambassador Vinita Mittal exhibiting "Behavior of Light" at the OP15 Optics Outreach Games.

\section{CONSIDERATIONS FOR OVERSEAS WORKSHOPS}

This section considers issues specific to conducting outreach in the form of school workshops. These can include lecture and/or classroom formats. The audience in a typical workshop includes school students from a specific 
age group with level-specific prior background knowledge, as well as their teacher(s). The class size usually varies between 15 and 30 pupils for a classroom workshop, and between 50 and 300 pupils, depending on the class and cohort size, for an assembly lecture.

\subsection{Topical Coverage and Format}

Content inclusion, i.e. 'what' and 'how much', is dictated by the educational level of the students and the allotted time for the engagement. For an assembly lecture, where students from different class levels may be simultaneously present, a general, non-technical talk about a topic on light or optics serves best to engage all students. For instance, in 2015, an appropriate topic could cover IYL 2015 and the applications of light in everyday life. The talk duration should not be excessively long, and particularly for primary school students, it should be moderated to no longer than 20 to 45 minutes, given their relatively short attention span. The use of adequately prepared and visually appealing demonstrations and videos at timely intervals can further enhance the engagement with the audience.

A classroom workshop for students from the same level can be more focused. The coverage should aim to align well with and complement the school's own science curriculum. Given the smaller class size (15-30 pupils), the engagement can be more technical, spread out, and interactive, than a lecture. A strategy we used is to break the class into groups and rotate them through a number of optics 'stations', each covering experiments on a different topic. Each station is supervised by a demonstrator, and a lone ambassador may enlist the help of the school's teachers to staff other stations.

\subsection{Equipment}

When exhibiting at a fair, the audience interacts with kits and experiments on an individual basis, and so it is sufficient to use small, portable, and few items. In contrast, a class workshop of the aforementioned format is better served by larger and more interactive equipment, since it is young students who will be handling it. A solution to the prohibitive size restrictions of international travel is the possibility of making use of the hosting school's resources. Many school science laboratories stock mirrors, tanks, retort stands, etc., which can all be used to create optics experiments. If time permits, some experiments can even be constructed after arriving at the destination city using materials from local stationery stores. These can also be donated to the host school after the event and reused in their curriculum.

\subsection{Language}

Although English is the lingua franca internationally, some care must be taken when communicating with young students in countries where the common first language is not English. Demonstrators need to observe patience and may need to restrict explanations to using only simple vocabulary. It helps if the demonstrator is fluent in the national language and this can be an alternative to English. Otherwise, school teachers can function as translators, though this may have implications with respect to the time needed to run activities and therefore must be accounted for in the plan.

\subsection{Case Example: Workshop at St Joseph's Institution Junior}

First author Nicholas Wong conducted a Lightwave event, called "Because Light Matters", at St Joseph's Institution Junior (SJIJ), a primary school in Singapore, on 15 July 2016 while on vacation back home. He is an alumnus of the school (formally known as St Michael's School). A local friend of his, Ryan Kok (also an alumnus), came along to assist.

The event, which spanned half a day, comprised two parts. In the morning, a 30-minute talk, on the origins and uses - notably the internet - of light as well as IYL 2015, was given to about 240 Primary 4 students (9-10year-olds). At various points, the students were asked questions and those who volunteered answers were awarded with an SPIE IYL 2015 lapel pin (Fig. 4, left). The talk concluded with a demonstration of the Tyndall-Colladon experiment. This was followed immediately by the students' recess and many intrigued students stayed behind to get a closer look (Fig. 4). 

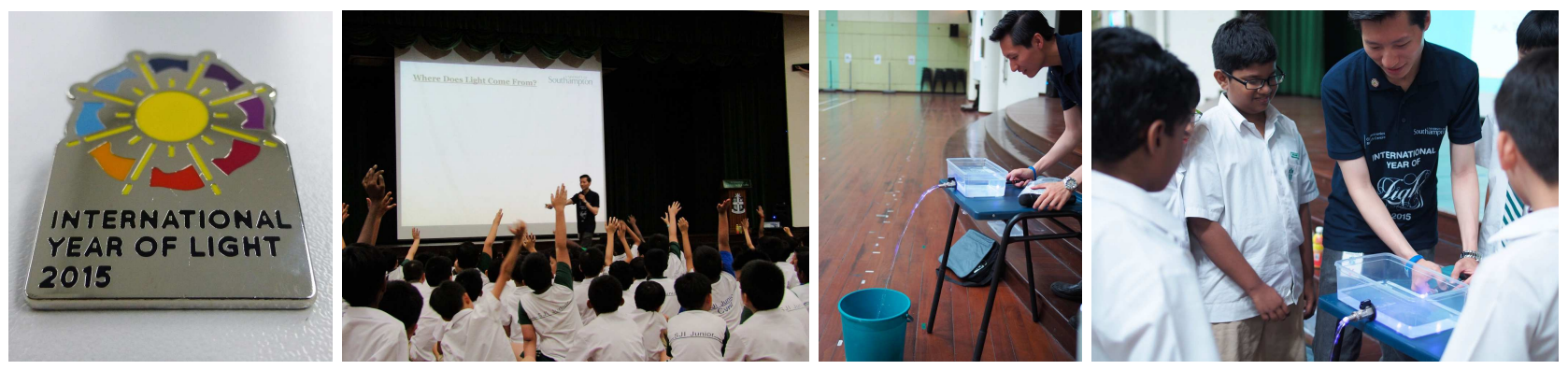

Figure 4: Because Light Matters lecture at SJIJ. (Left to right) SPIE IYL 2015 giveaway pin; Lightwave ambassador Nicholas Wong addresses Primary 4 students; demonstrating the Tyndall-Colladon experiment using a portable tank.

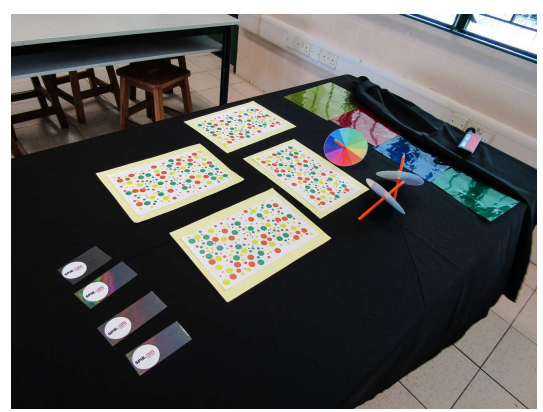

(a)

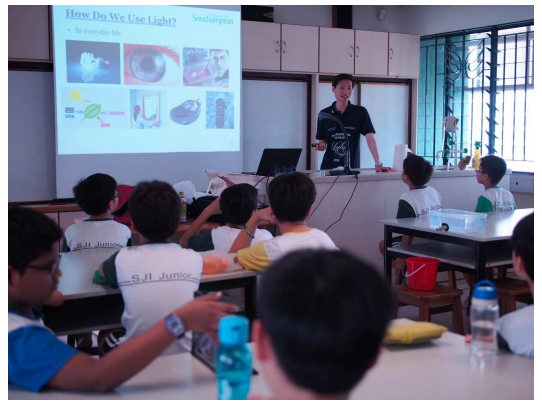

(d)

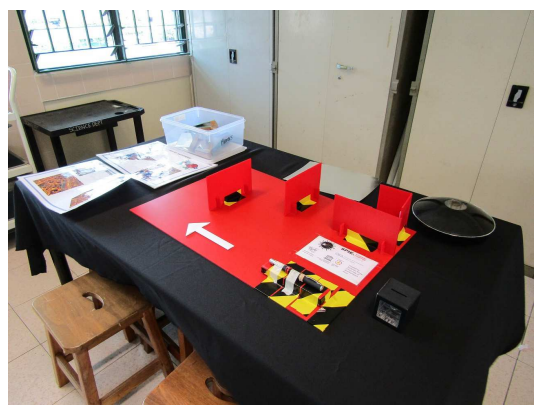

(b)

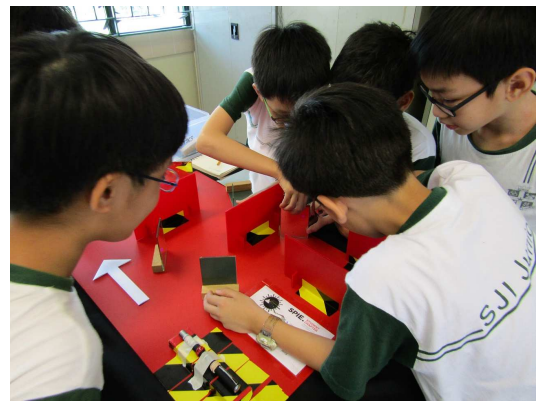

(e)

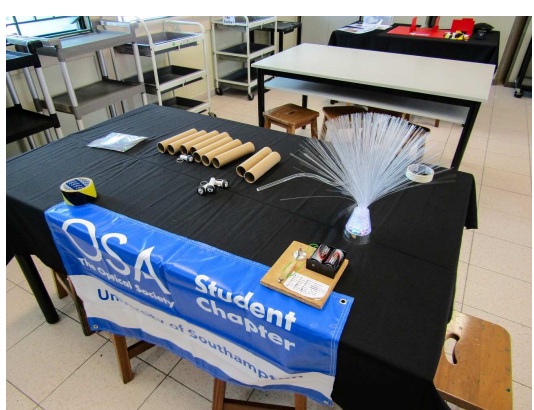

(c)

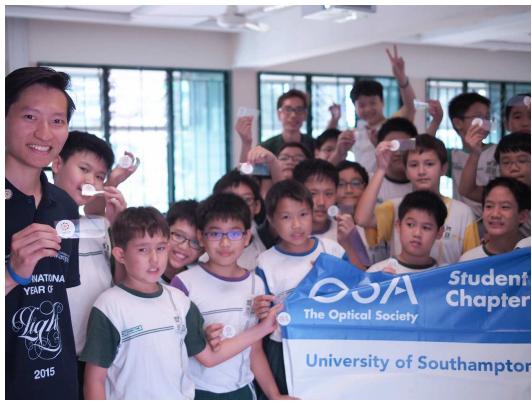

(f)

Figure 5: Because Light Matters workshop at SJIJ. (a) EM Spectrum station. (b) Mirrors Er Optical Illusions station. (c) Optical Fibers 85 Telecommunications station. (d) Nicholas Wong introduces students to the uses of light. (e) Pupils solving the mirror maze. (f) Students pose with diffraction gratings.

In the afternoon, a 50-minute workshop was conducted for a class of 25 Primary 5 pupils (10-11-year-olds) in the school's science laboratory (see Fig. 5). After a short introduction, the class was split into three groups that rotated through three stations around the laboratory:

1. Electromagnetic (EM) Spectrum (Fig. 5a). Students learned about the EM spectrum and color composition using color spinners, filter sheets, diffraction gratings, and an ultraviolet (UV) lamp with glow-in-the-dark bits. This station was self-exploratory and unsupervised.

2. Mirrors 8 Optical Illusions (Figs. 5b and 5e). Students had to get a laser beam spot around a maze by using mirrors. They also perceived image formation and optical illusion effects caused by planar and concave mirrors. The mirror maze was constructed using corrugated plastic sheets supplied by the school. The school also provided the mirrors. This station was supervised by one demonstrator. 
3. Optical Fibers 83 Telecommunications (Fig. 5c). Students were shown light guidance via total internal reflection. They also played with a home-made Morse code circuit and in pairs, emulated fiber communications: one student sent a Morse-coded message through a cardboard tube by turning a flashlight on and off and his partner had to decode the message by only looking at the light signals without any verbal communication. Several real commercial optical fiber samples were shown to them. This station was supervised by one demonstrator.

To assess learning outcomes, the class concluded with pupils each answering a multiple-choice-question worksheet. These were marked immediately and served to reinforce what the students had learned during the session. The whole event was featured in the school's social media ${ }^{30}$ as well as its official annual magazine.

\section{A PORTABLE OPTICS KIT FOR OUTREACH ABOARD}

We present a kit containing experiments and equipment covering various optics themes. This kit is portable; does not require mains power; can be transported, set up, and demonstrated by one person; and fits on a $4 \mathrm{ft} \times 2 \mathrm{ft}$ table when all items are laid out. We call this the "Compact Optics Suite".

\subsection{Contents and Presentation}
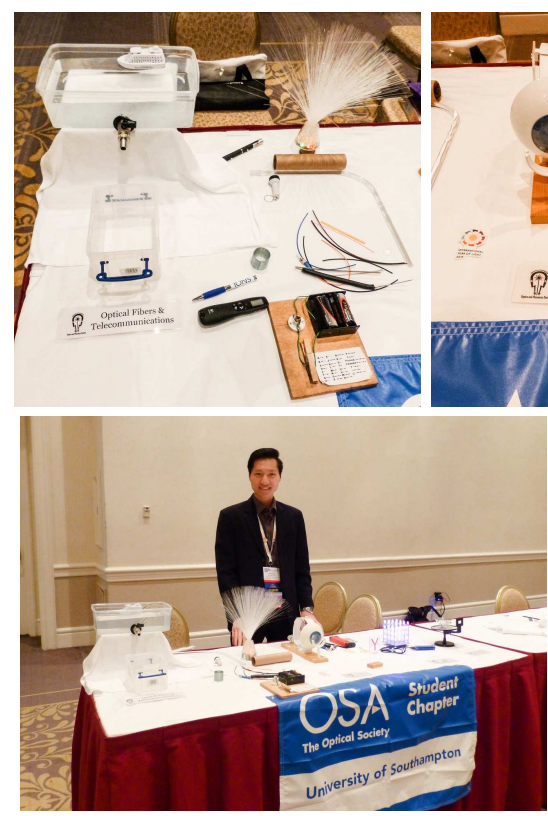
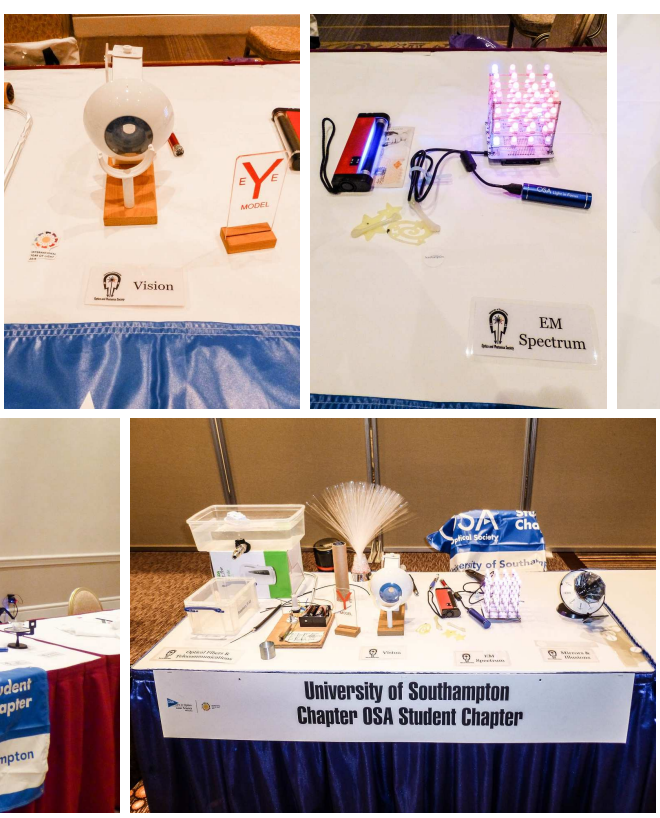
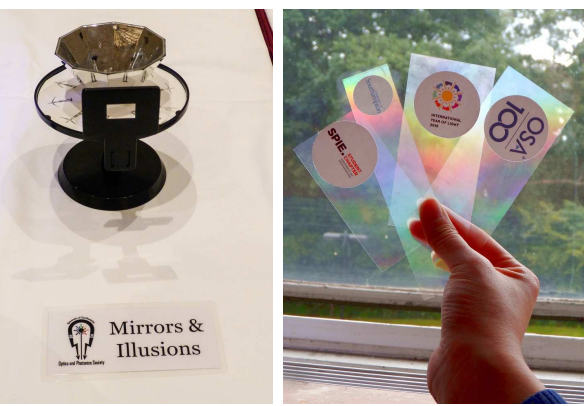

THE OPTICAL SOCIETY

CERTIFICATE OF ACHIEVEMENT

This certifies that the OSA Student Chapter at

University of Southampton

2015 Student Chapter Competition

IYL-To-Go
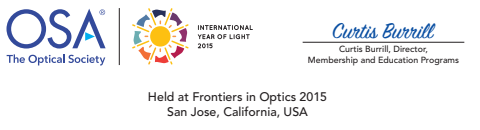

Figure 6: Portable Lightwave kit at $2015 \mathrm{FiO} / \mathrm{LS}$ conference. Top row: thematically laid out equipment; (left to right) Optical Fibers 85 Telecommunications, Vision, EM Spectrum, and Mirrors 85 Illusions. Top right: Diffraction grating giveaways. Bottom row: (left) kit displayed by Nicholas Wong for EDAY event; (middle) kit displayed on a $4 \mathrm{ft} \times 2 \mathrm{ft}$ table for OSA IYL-To-Go competition; (right) IYL-To-Go award certificate.

The kit contains items covering four optics themes:

1. Mirrors 85 Illusions - praxinoscope

2. EM Spectrum - laser pointer + diffraction gratings; LED matrix; UV lamp + bank note + glow-in-the-dark bits

3. Vision - hand-built human eye model + 3-bulb LED flashlight 
4. Optical Fibers 83 Telecommunications - fiber optic fountain; mini slinky; cardboard tube + flashlight keychain; laser pointer + Perspex waveguide; commercial fiber samples; hand-built Morse code circuit; laser pointer + tap and nozzle + translucent watertight boxes for the Tyndall-Colladon experiment (including an additional box to elevate the water source tank)

All equipment can be packed into one tote bag* (for the human eye model, fiber optic fountain, and Perspex waveguide) and two translucent boxes ${ }^{\dagger}$ (one for the LED matrix and the other for everything else) that double as tanks for the Tyndall-Colladon experiment, a travel-size version of Fig. 1e. Fig. 6 shows the items laid out thematically. The left-to-right arrangement can follow a logical topical progression, but is not critical. 1-3 minutes of brief demonstration and explanation per theme suffices, making the engagement last about 10 minutes.

More information on the demonstration items and where to find or purchase them is provided in our previous paper, Ref. 4.

\subsection{IYL-To-Go Competition and Science Educators Day}

The Compact Optics Suite was presented, by author Nicholas Wong, during the OSA "IYL-To-Go" Student Chapter Competition at the October, 2015 Frontiers in Optics/Laser Science (FiO/LS) conference in San Jose, CA, USA (Fig. 6, bottom middle). Participants had to "present their best ideas for youth education outreach" 26 to appointed judges. Of the 19 participating chapters, our chapter was selected as the Grand Prize Winner (Fig. 6, bottom right). Feedback from the judges indicated that organized themes, simplicity, and accessibility to young students with little optics background were favorable features of our kit. Some found the hand-built human eye model especially interesting. ${ }^{31}$

During the conference, the kit was also presented at the Science Educators Day (EDAY), depicted in Fig. 6, bottom left. This was an event to showcase educational optics demonstrations to local American educators and teachers.

\section{CONCLUSIONS}

Our outreach has greatly benefited from IYL 2015, which encouraged us to have a more international approach to our activities. In this paper, we have discussed a range of strategies to issues characteristic of conducting outreach endeavors abroad, for exhibition and school workshop and lecture formats. We have also presented a portable demonstration kit that is demonstrable by a single traveling ambassador. We hope that this paper serves as a helpful resource to benefit anyone considering overseas events for their local educational outreach programs.

\section{ACKNOWLEDGMENTS}

The authors wish to thank everyone in the Lightwave Roadshow team. We also thank John Taylor from OSA and Lauren Mecum from IPS for providing useful grants information. We are also grateful to our many collaborators, partners, event hosts, conference organizers, and sponsors (mentioned in the paper), as well as the now-ended EPSRC Centre for Innovative Manufacturing in Photonics (grant EP/H02607X/1), for supporting our work and enabling the continued development of the roadshow.

\section{REFERENCES}

[1] Foreman, H. D., Parmigiani, F. R., Roelens, M. A., and Simpson, R. E., "The lightwave roadshow," Proc. SPIE 9664, 140-148 (2005).

[2] "University of Southampton Optics and Photonics Society." Optics and Photonics Society, http://osa.or c. soton.ac.uk. (Accessed: 18 July 2016).

[3] Bricchi, E., Baggett, J. C., Guilhot, D. A., and Musgrave, I. O., "The lightwave road show," Proc. SPIE 9663, 96631L (2003).

${ }^{*}$ This black-and-white bag is visible on the chair in Fig. 6, top left image.

${ }^{\dagger}$ These, and an opaque box acting as a stand, are visible on the table's left-hand side in Fig. 6, bottom middle image. 
[4] Wong, N. H. L., Posner, M. T., and John, P. V., "The Lightwave program and roadshow: An overview and update," Proc. SPIE 9793, 97932V (2015).

[5] "Learn with US (Outreach)." University of Southampton, http://www. southampton.ac.uk/schools-col leges/learn-with-us-outreach.page. (Accessed: 29 July 2016).

[6] Posner, M. T., John, P. V., Wong, N. H. L., Mittal, V., and Nunez-Velazquez, M. M., "From school classes to UNESCO: IYL-enabled environments for tackling the STEM skills shortage through student-led outreach," Proc. SPIE 9946, 9946-6 (2016).

[7] Posner, M. T., John, P. V., Standen, D., Wheeler, N. V., van Putten, L. D., Soper, N., Parsonage, T. L., Wong, N. H. L., and Brambilla, G., "Reflecting Photonics: Reaching new audiences through new partnerships - IYL 2015 and the Royal Horticultural Society Flower Show," Proc. SPIE 9946, 9946-2 (2016).

[8] UN General Assembly, Resolution 68/221, "International Year of Light and Light-based Technologies, 2015." A/RES/68/221 (2014), available from undocs .org/A/RES/68/221.

[9] Curticapean, D. and Israel, K., "Photonics meet digital art," Proc. SPIE 9188, 91880M (2014).

[10] Curticapean, D., "International Year of Light 2015 opens new dimensions in optics and photonics education," Proc. SPIE 9793, 979308 (2015).

[11] "Artistic activities promoting IYL 2015 to reach out wider crowds." IYL 2015 Blog, 1 October 2015, https://light2015blog.org/2015/10/01/artistic-activities-promoting-iyl-2015-to-reac h-out-wider-crowds/. (Accessed: 28 July 2016).

[12] "Every Picture tells a Story I." IYL 2015 Blog, 21 January 2016, https://light2015blog.org/2016/01/ 21/every-picture-tells-a-story-i/. (Accessed: 28 July 2016).

[13] "Every Picture tells a Story II." IYL 2015 Blog, 22 January 2016, https://light2015blog.org/2016/01 /22/every-picture-tells-a-story-ii/. (Accessed: 28 July 2016).

[14] "Hundreds of people meet Lightwave at the Big Bang Fair." Optoelectronics Research Centre, 2014, http: //www.orc.soton.ac.uk/lightwavebb2014.html. (Accessed: 19 July 2016).

[15] "Light Blox Kit: International Year of Light Edition." Laser Classroom, http://store.laserclassroom. com/tech-light-lab-light-science-kit. (Accessed: 19 July 2016).

[16] "Student Author Travel Grants." SPIE, https://spie.org/membership/student-members/student-aut hor-travel-grants. (Accessed: 19 July 2016).

[17] "Chapter Management." SPIE, https://spie.org/membership/student-members/student-chapters/c hapter-management\#Officer_Travel_Grant. (Accessed: 19 July 2016).

[18] "Student Leadership Conference Grant." OSA, http://www.osa.org/en-us/membership_education/stu dent_services/student_chapter_benefits/annual_student_leadership_conference/. (Accessed: 19 July 2016).

[19] "Public Engagement with Research (PER) - Development Funding Call 2016/17." University of Southampton, 2016, http://www. southampton.ac.uk/per/support/funding.page. (Accessed: 19 July 2016).

[20] "Future Photonics Hub demonstrates excellence in outreach." The Future Photonics Hub, 17 March 2016, http://photonicshubuk.org/news/future-photonics-hub-demonstrates-excellence-in-outr each/. (Accessed: 20 July 2016).

[21] "SPIE Education Outreach Grants Program." SPIE, http://spie.org/education/education-outreach -resources/education-outreach-grants. (Accessed: 19 July 2016).

[22] "International Year of Light SPIE Student Chapter Activity Grants." SPIE, 2015, http://spie.org/abo ut-spie/international-year-of-light/iyl-activity-grants. (Accessed: 19 July 2016).

[23] "SPIE awards 26 grants for student IYL activities." SPIE Professional Magazine, April 2015, https://sp ie.org/membership/spie-professional-magazine/spie-professional-archives-and-special-cont ent/2015_april_archive/26-iyl-grants-for-students. (Accessed: 19 July 2016).

[24] "Centennial Chapter and Section Grants." OSA, http://www.osa.org/en-us/membership_education/s tudent_services/student_chapter_benefits/chapter_grants/. (Accessed: 19 July 2016).

[25] "Student Chapter and Local Section Excellence Prize." OSA, http://www.osa.org/en-us/membership_ed ucation/student_services/student_chapter_benefits/excellence_award_2014/. (Accessed: 19 July 2016). 
[26] "Student/Recent Grad Activities." OSA FiO/LS, 2015, http://www.frontiersinoptics.com/home/speci al-events/student-and-new-graduate-activities/\#StudentChapterCompetition. (Accessed: 19 July 2016).

[27] "IEEE Photonics Society Volunteer Opportunities." IEEE Photonics Society, 6 January 2015, http://pho tonicssociety.org/sites/default/files/IEEEPhotonicsSocietyVolunteerOpportunities1-6-15.p df. (Accessed: 19 July 2016).

[28] "Grants." EPS Young Minds, http://www.epsyoungminds.org/benefits/grants/. (Accessed: 19 July 2016).

[29] The YM Action Committee, "IYL2015 EPS Young Minds Activity Grants." European Physical Society, 6 January 2015, http://www.eps.org/blogpost/751263/205929/IYL2015-EPS-Young-Minds-Activity-G rants. (Accessed: 19 July 2016).

[30] St Joseph's Institution Junior. Facebook, 16 July 2015, https://www.facebook.com/sjijunior/posts/1 144579055555930. (Accessed: 31 July 2016).

[31] Lee, H., "A Day at FiO/LS: Highlights from the Student Chapter Competition." OSA FiO/LS, 27 October 2015, http://www.frontiersinoptics.com/home/about-fio-ls/the-fio-blog-luminous-insight s/2015/october-2015/a-day-at-fio-ls-highlists-from-the-student-chapte/. (Accessed: 27 July 2016). 